\title{
DESTERRITORIALIZAC̣ÃO/RETERRITORIALIZAC̣̃̃O: PROCESSOS VIVENCIADOS POR PROFESSORAS DE UMA ESCOLA DE EDUCAÇÃO ESPECIAL NO CONTEXTO DA EDUCAÇÃO INCLUSIVA
}

\author{
Eliene Nery Santana Enes* \\ Maria Gabriela Parenti Bicalho**
}

RESUMO: Este trabalho analisa os processos de desterritorialização/reterritorialização vivenciados por professoras de uma escola de Educação Especial da rede pública estadual do município de Governador Valadares (MG) no contexto das transformações da Educação Especial no sentido da educação inclusiva. A pesquisa foi construída em uma perspectiva interdisciplinar, pela articulação de concepções advindas dos campos da Educação e dos estudos territoriais, por meio das categorias território, territorialidade e desterritorialização/reterritorialização. Os dados, de caráter qualitativo, foram coletados com entrevistas semiestruturadas realizadas com seis professoras da escola. Os processos de desterritorialização/reterritorialização são compreendidos em três planos: histórico-temporal, espacial e simbólico. Aparecem marcados por modificações de práticas, concepções, códigos, saberes, por meio das quais as professoras abandonam alguns territórios e constituem outros. Por meio desses processos, fazem parte do devir da escola e da Educação Especial.

Palavras-chave: Educação Especial; Território; Desterritorialização/Reterritorialização.

\footnotetext{
* Mestre em Gestão Integrada do Território pela Universidade Vale do Rio Doce (UNIVALE); Professora do curso de Pedagogia da Universidade Vale do Rio Doce (UNIVALE). E-mail: eliene.nery@yahoo.com.br

* * Doutora em Educação pela Universidade Federal de Minas Gerais (UFMG); Professora do Programa de Pós-Graduação em Gestão Integrada do Território da Universidade Vale do Rio Doce (UNIVALE). E-mail: mgbicalho@hotmail.com
} 


\section{DETERRITORIALIZATION / RETERRITORIALIZATION: \\ PROCESSES EXPERIENCED BY TEACHERS IN A SCHOOL FOR SPECIAL EDUCATION IN THE CONTEXT OF INCLUSIVE EDUCATION}

ABSTRACT: This paper analyzes the processes of deterritorialization/ reterritorialization experienced by teachers in a public school for Special Education in the city of Governador Valadares (MG). These teachers' experiences take place in a context that has moved Special Education towards inclusive education. This research was built on an interdisciplinary perspective, which is related to concepts arising from the fields of Education and territorial studies, as well as the categories of territory and deterritorialization / reterritorialization. Qualitative data was collected using semi-structured interviews in which six teachers from a private school participated, as well as and document analysis. Deterritorialization / reterritorialization processes are understood at three levels: historical-temporal, spatial and symbolic. These are marked by changes in practices, concepts, codes, and knowledge, which altogether led to the formation of new territories.

Keywords: Special Education; Territory; Deterritorialization/Reterritorialization.

\section{Introdução}

A discussão proposta, neste artigo, insere-se no campo da educação, na perspectiva da inclusão, tratando, especificamente, dos processos vivenciados pelas professoras de uma escola de Ensino Especial da rede pública estadual do município de Governador Valadares (MG), no contexto das mudanças geradas pelas políticas públicas de caráter inclusivo.

Para abordar essa temática, apropriamo-nos de conceitos dos estudos territoriais na realização de uma pesquisa interdisciplinar, na qual dialogaram concepções teóricas dos campos da Educação e da Geografia. O campo da pesquisa foi a escola Estadual Paulo Campos Guimarães - EEPCG, cuja história permite a observação das transformações vivenciadas pelas instituições de atendimento às pessoas com necessidades especiais, no contexto da afirmação do paradigma da educação inclusiva, refletido em políticas públicas de inclusão. A pesquisa desenvolvida teve como objetivo geral compreender os processos de desterritorialização/reterritorialização vivenciados pelas professoras dessa escola no contexto das transformações da Educação Especial no município de Governador Valadares. Os dados foram coletados por meio de entrevistas semiestruturadas, realizadas com seis professoras da escola. 
Este artigo organiza-se em três seções. Inicialmente, apresentamos a perspectiva de diálogo entre os estudos territoriais e as questões da educação inclusiva, que possibilitou a adoção dos conceitos de desterritorialização/reterritorialização como categorias de análise para a compreensão dos processos vivenciados pelas professoras. $\mathrm{Na}$ segunda seção, abordamos o contexto de transformações da Educação Especial, no qual se desenvolvem tais processos: o paradigma da educação inclusiva, os reflexos das políticas públicas inclusivas no âmbito do município e a história da Escola Paulo Campos Guimarães. Na terceira seção, apresentamos uma análise das vivências das professoras, tomadas como processos de desterritorialização/reterritorialização, nos planos histórico-temporal, espacial e simbólico, e, finalmente, nas considerações finais, refletimos sobre o devir da escola.

\section{Território e educação: \\ delineando as categorias de análise}

\section{Território e territorialidade}

Os estudos territoriais abrangem um grupo heterogêneo de abordagens que questionam a concepção tradicional da Geografia, colocando em pauta a constituição do território a partir das ações dos sujeitos no espaço.

Etimologicamente, a palavra território, territorium, em latim, é derivada diretamente do vocábulo latino terra e era utilizada pelo sistema jurídico romano dentro do chamado jus terrendi, para designar "pedaço de terra apropriado, dentro dos limites de uma determinada jurisdição político-administrativa". Outro sentido do termo refere-se à grande proximidade etimológica existente entre terra-territorium e terreo-territor (aterrorizar aquele que aterroriza) (HAESBAERT, 2009, p.43).

Como mostra Haesbaert (2009), o verbete do dicionário Les mots de La Géographie, organizado por Roger Brunet e outros, reúne algumas acepções para território: malha de gestão de espaço, de apropriação não plenamente realizada; espaço apropriado, com sentimento ou consciência de sua apropriação; noção ao mesmo tempo jurídica, social e cultural, e mesmo afetiva. Alude-se, ainda, a um caráter inato ou natural de 
territorialidade humana. Haesbaert (2009) analisa o território sob diferentes enfoques e enumera três vertentes básicas, mas não excludentes, dentro do ideário do conceito: vertente econômica, vertente política e vertente cultural ou simbólica. A vertente econômica enfatiza a dimensão espacial das relações econômicas. O território, nessa perspectiva, é visto como fonte de recursos e/ou incorporado no embate entre classes sociais e na relação capital-trabalho. Por sua vez, a vertente política refere-se ao espaço-poder ou espaço político-jurídico. Nessa vertente, o território é visto como um espaço delimitado e controlado, através do qual se exerce um determinado poder, na maioria das vezes (mas não exclusivamente), relacionado ao poder político do Estado. Por fim, o autor apresenta a vertente cultural ou simbólico-cultural, que prioriza a dimensão simbólica e mais subjetiva, em que o território é visto, sobretudo, como produto da apropriação/valorização simbólica de um grupo em relação ao seu espaço vivido. Para o autor, "o território pode ser concebido a partir da imbricação de múltiplas relações de poder, do poder mais material das relações econômico-políticas ao poder mais simbólico das relações de ordem cultural" (HAESBAERT, 2009, p.79).

Haesbaert (2009) comenta a amplitude do conceito de território, que é central para a Geografia, e apresenta a possibilidade de pensar suas relações com a educação.

Território e territorialidade, por dizerem respeito à espacialidade humana, têm uma certa tradição também em outras áreas, cada uma com enfoque no território, em uma determinada perspectiva. Enquanto o geógrafo tende a enfatizar a materialidade, em suas múltiplas dimensões... a Ciência Política enfatiza sua construção a partir das relações de poder... a Economia, que prefere a noção de espaço à de território, percebe-o muitas vezes como um fator locacional ou como uma das bases da produção (enquanto força produtiva); a Antropologia destaca a sua dimensão simbólica... a Sociologia o enfoca a partir de sua intervenção nas relações sociais, em sentido amplo, e a Psicologia, finalmente, incorpora-o no debate sobre a construção da subjetividade ou identidade pessoal, ampliando-o até a escala do indivíduo (HAESBAERT, 2009, p.37).

Ao buscar as relações entre território e Educação, pensamos nas conexões entre os processos educacionais e as dimensões do território (política, econômica, cultural). O campo da educação abarca processos de aprendizado e de construção do conhecimento que se estabe- 
lecem a partir da relação com o outro. A prática pedagógica produz efeitos de transformação, interfere nos processos de desenvolvimento. Entendemos que a educação se faz no território, a partir das territorialidades.

Ao pensar o conceito de território para analisar uma realidade educacional, destacamos que esse conceito abriga relações entre pares que se mostram opostos e complementares e que são convidados a coexistirem e influenciarem-se mutuamente: materialidade e imaterialidade, complexidade e unicidade, diversidade e identidade, inclusão e exclusão, espaço e tempo, global e local, urbano e rural, indivíduo e sociedade. Entendemos essa "abertura à coexistência" como um elemento importante para compreender o fenômeno educativo, que se apresenta sempre composto por diferentes aspectos, materiais e simbólicos, e permeado pelas ações dos sujeitos, cuja compreensão não pode prescindir das noções de contradição, mudança, provisoriedade (FRANCO, 2003).

Essas possibilidades são confirmadas pela argumentação de Saquet (2010) de que território é um conceito complexo, substantivado por vários elementos:

Território é natureza e sociedade: não há separação: é economia, política e cultura; edificação e relações sociais; des-continuidades; conexão e redes; domínio e subordinação; degradação e proteção ambiental, etc. Em outras palavras, o território significa heterogeneidade e traços comuns, apropriação e dominação historicamente condicionadas; é produto e condição histórica e transescalar; com múltiplas variáveis, determinações, relações e unidade. É espaço de moradia, de produção de serviços, de mobilidade, de desorganização, de arte, de sonhos, enfim, de vida (objetiva e subjetivamente). O território é processual e relacional, (i)material, com diversidade e unidade, concomitantemente (SAQUET, 2006, p.83).

Para o autor, "o território é resultado e condição desta articulação e unidade” (SAQUET, 2007, p.69). É, portanto, multidimensional, funda-se na unidade e na diversidade. Nele, as relações sociais se materializam e se reproduzem, em movimentos desiguais, contraditórios e conflituosos. Outro aspecto salientado por Saquet (2007) nos parece importante e coerente com os estudos no campo educacional e traz à cena a noção de territorialização, que expressa o movimento do sujeito na produção do território. Segundo o autor, o processo de produção do território é construído pelo movimento histórico no qual o território é 
apropriado e erigido socialmente como resultado e condição do processo de territorialização. Portanto, essa produção é resultado do processo cotidiano de apropriação e domínio social e inscreve-se no estabelecimento das relações socioespaciais. "Os processos sociais e naturais, e mesmo nosso pensamento, efetivam-se na e com a territorialidade cotidiana. É aí, neste nível, que se dá o acontecer de nossa vida, e é nesta que se concretiza a territorialidade" (SAQUET, 2007, p.58).

Nesse contexto, complementa Saquet sobre os territórios e as territorialidades:

[...] são vividos, percebidos e compreendidos de formas distintas; são substantivados por relações. Homogeneidades e heterogeneidades, integração e conflito, localização e movimento, identidades, línguas e religiões, mercadorias, instituições, natureza exterior ao homem; por diversidade e unidade; (i)materialidade (SAQUET, 2010, p.25).

Transpondo essas reflexões sobre o conceito de território para a abordagem que, aqui, se pretende fazer da Educação Especial, voltamo-nos para a Escola de Educação Especial tomada como campo de pesquisa, considerando-a um território. Em suas dimensões - política, econômica e cultural/simbólica - os indivíduos e/ou grupos estabelecem relações. No presente estudo, a dimensão cultural ou simbólico-cultural será privilegiada, uma vez que o território é considerado, em seu aspecto de subjetividade, como produto da apropriação/valorização simbólica de um grupo em relação ao seu espaço vivido (HAESBAERT, 2009).

Na concepção de Raffestin (1993, p.144), o território se forma a partir do espaço; é o resultado de uma ação conduzida por um ator sintagmático (ator que realiza um programa). No território, projetou-se um trabalho, seja energia ou informação, e que, por consequência, revela relações marcadas pelo poder. O espaço é anterior ao território, podese dizer que é matéria-prima. Também na perspectiva desse autor, o conceito de territorialidade nos parece interessante. Para ele, a territorialidade "reflete a multidimensionalidade do 'vivido' territorial, pelos membros de uma coletividade, pelas sociedades em geral" (RAFFESTIN, 1993, p.158). A territorialidade se manifesta em todas as escalas espaciais e sociais, é a face "vivida" da "face agida" do poder. Raffestin afirma que "a análise da territorialidade só é possível pela apreensão das 
relações sociais recolocadas no seu contexto sócio-histórico e espaçotemporal" (RAFFESTIN, 1993, p.162). O autor define a territorialidade como um conjunto de relações que se originam de um sistema tridimensional sociedade-espaço-tempo, sendo a "soma" das relações mantidas por um sujeito com o seu meio.

Portanto, seguindo essa reflexão de Raffestin, entendemos que as territorialidades, no contexto da EEPCG, articulam as vivências dos sujeitos à organização da Educação Especial. A imbricação entre território e territorialidade, presente nas referências dos estudos territoriais, foi identificada por nós como uma perspectiva interessante para a análise de uma realidade educacional, pois reafirma o papel dos sujeitos como protagonistas, permitindo investigar seus movimentos, seus processos. Assim, na medida em que consideramos a Educação Especial e a EEPCG como territórios, podemos pensar que eles se constituem na territorialidade de seus atores, entre os quais as professoras. Em seu cotidiano de trabalho, elas ocupam e instituem a escola e a Educação Especial com práticas que mobilizam e constroem saberes e identidades. As práticas educativas, no coletivo da sala de aula, trazem em si a experiência relacional, e, nessas relações, com o aluno, produzem territorialidades que marcam a identidade das professoras, na singularidade de professoras de escola especial.

Ao apresentar nossas leituras e nossas análises sobre território e territorialidade, buscamos mostrar o caminho teórico que fundamentou a realização da pesquisa. Ao procurar estabelecer diálogos entre o conceito de território e uma realidade da Educação Especial, chegamos à compreensão de que a apreensão das territorialidades vivenciadas pelas professoras da EEPCG dar-se-ia por meio da compreensão das relações sociais recolocadas no seu contexto sócio-histórico e espaçotemporal. Ao adotar o conceito de território para analisar uma realidade do campo da educação, buscamos aproximar-nos da compreensão dessa realidade em sua complexidade, destacando os sujeitos que, envolvidos em práticas educativas, movimentam aspectos de objetividade e subjetividade, necessidade e desejo, em relações contraditórias e múltiplas consigo mesmo e com os outros. Entendemos, então, a afirmação de Saquet de que a abordagem dos estudos territoriais pretende contribuir para a "[...] elaboração de proposições teórico-metodológicas que sejam coerentes com o real" (SAQUET, 2007, p.56). 
O caminho teórico que fomos construindo ao longo deste trabalho, na tentativa de compreender as vivências das professoras da EEPCG no contexto das transformações da Educação Especial, levounos, finalmente, aos conceitos de desterritorialização/reterritorialização. $\mathrm{Na}$ verdade, encontramos neles um recurso para compreender essas vivências, quer dizer, concluímos que seria interessante nomeá-las - e, portanto, abordá-las - como processos de desterritorialização/reterritorialização. No próximo item, buscamos apresentar esses conceitos, mostrando os motivos dessa escolha teórica.

\section{Desterritorialização/reterritorialização}

Conforme Haesbaert (2002, 2003, 2009), a temática da desterritorialização tem sido centro de discussões na última década. $\mathrm{O}$ mundo vive atualmente um de seus períodos mais contraditórios e complexos, com os efeitos da modernização que impõem novas geometrias aos espaços. Conforme Haesbaert, a desterritorialização "é tratada como uma das marcas fundamentais de nosso tempo" (HAESBAERT, 2003, p.113). O autor esclarece que, nos processos de desterritorialização/ reterritorialização, estão imbricadas as dimensões política e cultural. Um processo de desterritorialização pode ser tanto simbólico, com a destruição de símbolos, marcos históricos, identidades, quanto concreto, material - político e/ou econômico, pela destruição de antigos laços/fronteiras econômico-políticos de integração. Também os indivíduos, classes e grupos sociais incorporam sempre, embora em diferentes níveis e escalas, perspectivas desterritorializadas/desterritorializantes (HAESBAERT, 2003, p.181).

Para a abordagem dos conceitos de desterritorialização/reterritorialização, recorre-se aos filósofos franceses Deleuze e Guattari. Em entrevista, Deleuze afirma:

[...] construímos um conceito de que gosto muito, o da desterritorialização. [...] precisamos às vezes inventar uma palavra bárbara para dar conta de uma noção com pretensão nova. A noção com pretensão nova é que não há território sem um vetor de saída do território, e não há saída do território, ou seja, desterritorialização, sem, ao mesmo tempo, um esforço para se reterritorializar em outra parte (DELEUZE apud HAESBAERT, 2009, p.99). 
Deleuze e Guattari são uma espécie de "pais" dessa terminologia, trabalhada, principalmente, em sua obra $O$ anti-Édipo (publicada, originalmente, em 1972) e desdobrada, sobretudo, em Mil platôs (1980) e "O que é a Filosofia?" (1992). O ponto fundamental, na obra dos autores, é que os territórios sempre comportam, dentro de si, vetores de desterritorialização e de reterritorialização.

Ao adotar essa perspectiva, em nossa análise, pretendemos "[...] operar por deslocamentos. Tomar conceitos de Deleuze e deslocá-los para o campo, para o plano da imanência que é a educação" (GALLO, 2008, p.54, grifo do autor). Assim, esses conceitos passam a ser dispositivos, agenciamentos, intercessores para pensar as transformações da Educação Especial, "dispositivos para produzir diferenças e diferenciações no plano educacional [...] uma abertura de possibilidades, incitação, incentivo à criação" (GALLO, 2008, p.54).

Para Deleuze e Guattari, território é um conceito fundamental da filosofia. No livro Micropolítica: cartografias do desejo, de Guattari e Ronilk (2010), a noção de território

[...] é entendida num sentido muito amplo, que ultrapassa o uso que fazem dele a etologia e a etnologia. Os seres existentes se organizam segundo territórios que se delimitam e os articulam aos outros existentes e aos fluxos cósmicos. O território pode ser relativo tanto a um espaço vivido, quanto a um sistema percebido no seio do qual um sujeito se sente "em casa". O território é sinônimo de apropriação, de subjetivação fechada sobre si mesma. Ele é o conjunto de projetos e representações nos quais vai desembocar, pragmaticamente, toda série de comportamentos, de investimentos, nos tempos e nos espaços sociais, culturais, estéticos, cognitivos (GUATTARI; RONILK, 2010, p.388).

Guattari e Ronilk (2010) apontam o território como sinônimo de apropriação, de subjetivação, sendo que:

O território pode se desterritorializar, isto é, abrir-se, engajar-se em linhas de fuga e até sair do seu curso e se destruir. A espécie humana está mergulhada num imenso movimento de desterritorialização, no sentido de que seus territórios "originais" se desfazem ininterruptamente com a divisão social do trabalho, com a ação dos deuses universais que ultrapassam os quadros da tribo e da etnia, com os sistemas maquínicos que a levam a atravessar, cada vez mais rapidamente, as estratificações materiais e mentais (GUATTARI; RONILK, 2010, p.388). 
O conceito de território é um agenciamento. Agenciamento, ${ }^{\mathrm{i}}$ conforme Guattari e Ronilk,

[...] é uma noção mais ampla do que as de estrutura, sistema, forma, processo, montagem, etc. Um agenciamento comporta componentes heterogêneos, tanto de ordem biológica, quanto social, maquínica, gnosiológica, imaginária. Na teoria esquizoanalítica do inconsciente, o agenciamento é concebido para substituir o "complexo" freudiano (GUATTARI; RONILK, 2010, p.381).

Os agenciamentos são dispositivos que conduzem tanto humanos como não humanos e que podem produzir individuação e singularização, ambas de caráter coletivo. Um território se constitui com os movimentos de agenciamentos maquínicos de corpos e agenciamentos coletivos de enunciação. Deleuze e Guattari utilizam-se da ideia de máquina para exprimir a hibridação existente nos processos de subjetivação, já que a máquina é o que humaniza o homem, assim como o homem, ao se maquinizar, subjetiva-se através da máquina. "A máquina é o conjunto de vizinhança homem-ferramenta-animal-coisa. Ela é a primeira em relação a eles, já que é a linha abstrata que os atravessa e os faz funcionar juntos" (DELEUZE; PARNET, 1998, p.122). As máquinas desejantes se constituem por agenciamentos maquínicos.

Haesbaert explica a construção do território pelos agenciamentos:

O território pode ser construído em um livro a partir do agenciamento maquínico das técnicas, dos corpos da natureza (as árvores), do corpo do autor e das multiplicidades que o atravessam, e do agenciamento coletivo de enunciação, neste caso um sistema sintático e semântico (HAESBAERT, 2009, p.126).

Além dos agenciamentos, outros movimentos do território são os processos de desterritorialização/reterritorialização. Para Haesbaert e Bruce, Deleuze e Guattari

[...] sempre tiveram no conceito de território e nos processos de desterritorialização e reterritorialização importantes ferramentas para o entendimento não apenas nas questões filosóficas, mas também das práticas sociais e na construção de um efetivo projeto político de libertação dos desejos, dos corpos, da arte, da criação e da produção da subjetividade (HAESBAERT; BRUCE, 2002, p.11). 
Entendemos a desterritorialização como o movimento pelo qual se abandona o território, "é a operação da linha de fuga", e a reterritorialização, como o movimento de construção do território (DELEUZE; GUATTARI, 1997b, p.224 apud HAESBAERT, 2009, p.127). Os agenciamentos têm como características os movimentos de desterritorialização/reterritorialização, os estados de coisas (agenciamentos maquínicos) e os enunciados (agenciamentos coletivos de enunciação). O movimento de desterritorialização produz, como já dissemos, linhas de fuga, que se podem reterritorializar em outros planos. De outro lado, o movimento de reterritorialização compreende as maneiras como um agenciamento compõe um plano de expansão do território (FERREIRA, 2010).

Adotamos, então, essas duas ferramentas, propostas por Deleuze e Guattari - a desterritorialização e a reterritorialização - para entender a experiência vivida pelas professoras da EEPCG em meio às transformações da Educação Especial no município de Governador Valadares. Podemos considerar elementos de desterritorialização as políticas de Educação Especial, os paradigmas da integração, as práticas pedagógicas, o espaço físico da EEPCG, que se expande, produzindo um novo território. No segundo movimento, os agenciamentos reterritorializam as políticas, os paradigmas e as práticas com novos agenciamentos maquínicos (os estados de coisas) e os enunciados (agenciamentos coletivos de enunciação), que são a enunciação do fazer prático, as ações. Nesse caso, a enunciação da reorganização da escola a partir da nova política de Educação Especial, das novas práticas, dos paradigmas da inclusão, do novo espaço físico. "O enunciado é o produto de um agenciamento, sempre coletivo, que põe em jogo, em nós e fora de nós, populações, multiplicidades, territórios, devires, afetos, acontecimentos [...]" (DELEUZE; PARNET, 1998, p.65).

A desterritorialização e a reterritorialização são processos indissociáveis. Se há um movimento de desterritorialização, haverá também um movimento de reterritorialização, podendo-se afirmar que eles são concomitantes. "Temos que pensar a desterritorialização como uma potência perfeitamente positiva, que possui seus graus e seus limiares e que sempre é relativa, tendo, em reverso, uma complementaridade na reterritorialização" (DELEUZE; GUATTARI, 2009, p.69). O exemplo dado por Haesbaert auxilia na compreensão desses processos: 
O boia-fria morador de periferias urbanas: este trabalhador está em constante processo de desterritorialização e reterritorialização. Enquanto a época da colheita não chega, ele habita a periferia urbana e está imerso em um conjunto de agenciamentos maquínicos de corpos e coletivos de enunciação, totalmente diferentes dos agenciamentos que teria como trabalhador assalariado. Enquanto morador urbano, ele possui uma determinada dinâmica em sua territorialidade. $\mathrm{Na}$ periferia, ele pode construir uma série de territórios e passa em cada um deles no decorrer do dia, como o operário da fábrica. É evidente que seus territórios serão outros, mas a dinâmica de passagem por vários territórios é semelhante. Existe seu território de morador, onde ele conhece seus códigos territoriais e as relações de poder que compreendem sua "comunidade". Existe o território de trabalho, que é muito mais difícil de delimitar do que o do operário fabril. Em um dia, ele é pedreiro; no outro, porteiro, segurança, etc. Quando chega a época da colheita, ele se desterritorializa e abre os agenciamentos e vai se reterritorializar no trabalho na lavoura. Quando este termina, ele novamente vivencia os agenciamentos da vida urbana (HAESBAERT, 2009, p.139).

Nesse contexto, a vida é um constante movimento de desterritorialização/reterritorialização. Estamos sempre passando de um território a outro, abandonando territórios, criando novos territórios. Tratase de uma desterritorialização/reterritorialização cotidiana, em que se abandona o território, mas não se destrói o território abandonado (HAESBAERT, 2009). "A reterritorialização consistirá numa tentativa de recomposição de um território engajado num processo desterritorializante" (GUATTARI; RONILK, 2010, p.388).

As perspectivas teóricas de desterritorialização/reterritorialização nos permitem lançar um determinado olhar sobre nosso objeto de estudo: as vivências das professoras de Educação Especial no contexto das transformações no sentido da educação inclusiva. Escolhemos esse olhar pelo reconhecimento do movimento, da mudança e, ao mesmo tempo, das permanências. Um território é abandonado e um outro território é construído. Aqui se revela o ponto de partida para a presente proposta de análise: os processos de desterritorialização/reterritorialização vivenciados pelas professoras da Escola Estadual Paulo Campos Guimarães, no contexto das transformações da Educação Especial, no município de Governador Valadares. "As territorialidades são, pois, atravessadas, de um lado a outro, por linhas de fuga que dão prova da presença, nelas, de movimentos de desterritorialização e reterritorialização" (DELEUZE; GUATTARI, 2009, p.71). 
Seguindo, pois, o caminho dos conceitos de território, territorialidade, desterritorialização/reterritorialização, chegamos a uma possibilidade de nomear aquela parte da realidade das transformações da Educação Especial em Governador Valadares, que foi trazida, inicialmente, como foco de interesse. Passamos, então, a falar dos processos de desterritorialização e reterritorialização vivenciados pelas professoras da EEPCG no contexto das transformações da Educação Especial em Governador Valadares. Esse referencial teórico nos leva de volta a essa realidade e coloca a necessidade de analisá-la mais detidamente, pois é nela que se constituem esses processos. Assim, no próximo item, abordamos a Educação Especial em Governador Valadares, em suas transformações no sentido da educação inclusiva.

\section{A Educação Especial no sentido da educação inclusiva: as transformações de uma escola em um contexto de mudanças}

\section{A Educação Especial e o paradigma da inclusão: transformações na esfera do município}

Abordamos, neste item, a educação inclusiva, como uma proposta educativa que pretende trazer novos valores educacionais e metodologias de ensino que permitam aos alunos com diferentes capacidades aprender juntos, sem separação pelo nível socioeconômico, etnia, cultura, deficiência. A educação inclusiva pressupõe "[...] ressignificar o papel do professor, da escola, da educação e das práticas pedagógicas que são usuais no contexto excludente do nosso ensino em todos os seus níveis" (MANTOAN, 2006, p.54-55). Apontam-se mudanças nas concepções educacionais e nos modos de funcionamento das escolas "regulares", a partir de um novo modelo de escola, no qual é possível, afirma Glat (2007), o acesso e a permanência de todos os alunos e no qual os mecanismos de seleção e discriminação até então utilizados são substituídos por procedimentos de identificação e remoção de barreiras de aprendizagem. Na visão da autora, esse novo modelo de escola precisa formar seus professores e equipe de gestão, modificar sua estrutura, organização, seu projeto político-pedagógico, seus recursos didáticos, metodologias e estratégias de ensino. Para acolher todos os alunos, sobretudo, a 
escola precisa transformar suas intenções e escolhas curriculares e oferecer um ensino diferenciado que favoreça o desenvolvimento e a inclusão social. Ao promover essa reforma dos sistemas educacionais, a educação inclusiva coloca em questão as teorias e pressupostos inerentes à Educação Especial, que também passa por um processo de ressignificação.

No Brasil, nos anos 1990, as discussões, em âmbito mundial, vão ao encontro de diferentes movimentos sociais brasileiros que defendiam o acesso à educação de pessoas com deficiência, e também de outros grupos. Essa confluência de ideias passa a se fazer presente nos fóruns e debates educacionais, materializada, posteriormente, em propostas do Ministério da Educação. Nesse contexto, com a presença atuante de dispositivos legais em favor da garantia do direito de "todos" à educação e ao acesso à escola, impõe-se a necessidade de reestruturação da Educação Especial no Brasil. A Política Nacional de Educação Especial na Perspectiva da Educação Inclusiva, de janeiro de 2008, é um marco importante desse movimento. Reflete a ampla discussão realizada em diversos fóruns educacionais sobre inclusão no país, as conquistas do movimento das pessoas com deficiência, bem como os avanços dos marcos legais educacionais. $O$ documento configura a educação inclusiva como uma ação política, cultural, social e pedagógica, em defesa do direito de todos a uma educação de qualidade e da organização de um sistema educacional inclusivo.

$\mathrm{Na}$ perspectiva da educação inclusiva, a Educação Especial passa a integrar a proposta pedagógica da escola regular, promovendo o atendimento às necessidades educacionais especiais de alunos com deficiência, transtornos globais do desenvolvimento e altas habilidades/ superdotação. $O$ atendimento às necessidades educacionais especiais desses alunos é realizado de forma articulada com o ensino comum.

No Brasil, essa modalidade educativa apresentou, até os anos 80, características que consolidaram um distanciamento do sistema regular de ensino, entre as quais a legitimação de instituições especiais como as mais adequadas para o atendimento educacional das pessoas com deficiência e o afastamento do Estado, em relação às questões educacionais das pessoas com deficiência, pela transferência da responsabilidade da educação dessa população para o setor privado. Nesse contexto, instituições especializadas de caráter privado com objetivos assisten- 
cialistas buscavam atender as demandas da Educação, em um processo caracterizado por Jannuzzi (2001, p.185) como “[...] uma parcial simbiose entre o público e o privado, que permite ao segundo exercer influência na determinação da política pública na área”.

Aconteceu assim no município de Governador Valadares. O atendimento à pessoa com deficiência teve inicialmente caráter assistencialista e foi realizado por instituições privadas. Nos anos 1990, as discussões sobre Educação Especial assumidas pelo Ministério da Educação - MEC começam a se manifestar no município. Em conformidade com as orientações legais da Secretaria de Educação Especial SEESP/MEC, a Secretaria de Estado da Educação de Minas Gerais criou a Diretoria da Educação Especial/DESP, em agosto de 2001, implantando o Projeto Piloto Escola Inclusiva, que se tornou Projeto Incluir. Governador Valadares tornou-se, em 2003, polo de disseminação do Programa Educação Inclusiva: direito à diversidade, da SEESP/MEC, que buscava subsidiar filosófica e tecnicamente o processo de transformação do sistema educacional em sistema educacional inclusivo e capacitar gestores e educadores para implementar a política de educação inclusiva. Esse fato refletiu positivamente na Educação Especial local, pois favoreceu o desenvolvimento do atendimento educacional especializado, o aumento de alternativas de formação continuada de professores e de discussões sobre educação inclusiva e suas práticas em todos os sistemas de ensino. Em 2005, foi criado o Centro de Referência e Apoio à Educação Inclusiva - CRAEDI, para oferecer o atendimento educacional especializado às escolas da rede municipal.

Esses projetos e iniciativas traçaram o caminho das transformações da Educação Especial em Governador Valadares, no sentido da educação inclusiva. Uma das instituições centrais nesse processo foi a escola escolhida como campo da pesquisa, cuja história permite enxergar os reflexos das mudanças geradas pelo paradigma da educação inclusiva.

\section{A Escola Estadual Paulo Campos Guimarães: de "Escola da APAE" a Unidade de Ensino Especial}

A Escola Estadual Paulo Campos Guimarães está, em sua origem, ligada à Associação de Pais e Amigos dos Excepcionais de 
Governador Valadares (APAE/GV). Criada em 1974, sua denominação foi uma homenagem ao vice-presidente da APAE Nacional. A escola funcionava com parte de professores mantida pela APAE/GV em sistema de contrato e outra parte cedida pela Secretaria de Estado da Educação de Minas Gerais (SEE/MG). No final dos anos 80, a APAE/ GV solicita a estadualização da Escola Paulo Campos Guimarães, que continuou funcionando em convênio com o CEUS/APAE-GV, em prédio cedido pela Associação. Como lembram Glat (2007), Mazzotta (2005) e Jannuzzi (2001), a história dessa convivência ambígua entre o público e o privado legitimava as instituições especiais filantrópicas como as responsáveis pela educação especial.

A Escola Estadual Paulo Campos Guimarães destinava-se a atender alunos com necessidades educacionais especiais (deficiência física, motora, sensorial, mental ou múltipla), no Pré-Escolar e Ensino Fundamental, de $1^{\mathrm{a}}$ a $4^{\mathrm{a}}$ séries. A concepção educacional adotada, nessa época, era a concepção integracionista, que, conforme Glat e Fernandes,

[...] consistia na preparação de alunos em classes especiais e escolas especiais para serem integrados preferencialmente no ensino regular, recebendo atendimento paralelo em sala de recursos ou outras modalidades especializadas (GLAT; FERNANDES, 2005, p.3).

A ligação com a APAE enfraquecerá à medida que avançam, no município, as discussões e as ações no sentido da Educação Inclusiva, reflexo do que acontecia nacionalmente. Nesse processo, fortalece-se a construção de uma identidade própria da escola, como escola pública estadual de Educação Especial, com um papel específico no processo de inclusão das crianças e jovens com necessidades educativas especiais no sistema regular de ensino.

No ano de 2006, o Projeto Escolas Especiais: um novo tempo, da Secretaria de Estado da Educação de Minas Gerais, foi um marco desse processo. Desenvolvido numa ação conjunta entre a Superintendência de Educação/Diretoria de Educação Especial, Superintendência Regional de Ensino e a própria escola, visava a oferecer condições para que as escolas especiais estaduais se estruturassem para atuar na Rede de Apoio às escolas comuns públicas que têm alunos com necessidades educacionais especiais. No biênio 2005/2006, a escola favoreceu a inclusão em escolas comuns de grande número dos seus alunos, entre os 
quais, alunos com dificuldades de aprendizagem acentuadas, deficiência múltipla, deficiência mental leve e moderada e principalmente os alunos jovens e adultos. $\mathrm{Na}$ escola, permaneceram os alunos com maior grau de comprometimento, com necessidade de apoio constante e intenso, aos quais a escola comum ainda não poderia oferecer atendimento.

No ano de 2008, a Escola Estadual Paulo Campos Guimarães e a APAE/GV desfazem a sua parceria. A escola conquistou sede própria, em imóvel adaptado, alugado pela Secretaria de Estado de Educação de Minas Gerais. Juntamente com a redução do número de alunos, esse episódio teve grande repercussão sobre a instituição e seus sujeitos, levando à reconfiguração de suas atividades e de suas propostas. Até então, a Escola Paulo Campos Guimarães era conhecida como "escola da APAE", sendo necessária, a partir da separação, a construção de uma nova identidade. Esse processo de transformação da EEPCG foi vivido de diversas maneiras por seus diferentes atores. Sentimentos de indignação, aceitação, medo, esperança, entre outros, foram expressos pela comunidade escolar no percurso das transformações, na direção da proposta inclusiva.

Em 2009/2010, a Escola Estadual Paulo Campos Guimarães deu continuidade ao processo de transformações na perspectiva da educação inclusiva. Outros alunos foram incluídos em classes comuns do ensino regular, novos atendimentos foram ofertados, outros extintos, e seu projeto político-pedagógico foi reconstruído, em busca de novas possibilidades da Educação Especial na perspectiva da educação inclusiva.

Atualmente, a Escola Estadual Paulo Campos Guimarães está organizada em consonância com a LDBEN/96, a Orientação SD n ${ }^{\circ}$ 01/2005, de 09 de abril, da Secretaria de Estado de Educação de Minas Gerais, a Política Nacional de Educação Especial na Perspectiva Inclusiva (2008), entre outros documentos e diretrizes da SEE/MG. Funciona em dois turnos, matutino e vespertino, e oferece escolarização exclusivamente aos alunos com necessidades educacionais (alunos com deficiência múltipla, cognitiva e transtorno global de desenvolvimento).

Sua equipe é constituída de professores de educação básica, com cursos adicionais específicos em Educação Especial, e por profissionais de diferentes áreas: psicólogo, assistente social, fonoaudiólogo, fisioterapeuta, pedagogo. A escola também participa de capacitação de 
professores da rede estadual de ensino, a convite da SRE de Governador Valadares e/ou da SEE/MG, e colabora, a partir de demanda de outras escolas estaduais, com processos de avaliação de alunos, na identificação de necessidades educacionais especiais.

A história da Escola Estadual Paulo Campos Guimarães mostra, portanto, as transformações vivenciadas por uma instituição de Educação Especial na esteira das mudanças paradigmáticas desse campo, na direção da educação inclusiva. A partir dos diálogos estabelecidos entre os estudos territoriais e educação, especificamente nos processos de transformação da Educação Especial, buscamos compreender as questões que orientam esta pesquisa: como foram vivenciadas, pelas professoras da EEPCG, as transformações da Educação Especial na direção inclusiva? Compreendendo a Educação Especial e a EEPCG como territórios, que territorialidades foram construídas e reconstruídas pelas professoras nesse processo de mudança? Esses processos podem ser compreendidos como processos de desterritorialização/reterritorialização? Buscando responder a essas perguntas, voltamo-nos para essas professoras e buscamos ouvi-las em entrevistas. Partimos de uma pergunta inicial: Como se deram as mudanças da EEPCG no contexto das transformações da Educação Especial na direção inclusiva? A partir de então, estabeleceu-se um diálogo, novas perguntas foram feitas a partir das respostas, produzindo novos relatos, evocando lembranças que despertaram emoções e provocando a expressão de desejos, esperança e medos em relação ao futuro.

As seis entrevistadas eram professoras efetivas de educação básica, regentes de classe de ensino especial, com tempo de trabalho na EEPCG que variava de 11 a 20 anos, todas com cursos de capacitação em Educação Especial/Inclusiva, com formação de nível superior e pós-graduação lato sensu. Refletindo sobre suas falas, buscamos compreender como vivenciaram as transformações que as mudanças na Educação Especial ocasionaram em suas práticas profissionais, em sua identidade como professoras de ensino especial, em seus saberes. Por meio das noções de desterritorialização/reterritorialização, realizamos uma análise dessas transformações, propondo uma maneira de compreender as experiências vivenciadas por essas professoras. 


\section{Movimentos de desterritorialização/reterritorialização}

As professoras entrevistadas relataram suas trajetórias, enfatizando um processo no qual se constituíram professoras de educação especial, as dificuldades, as buscas e as conquistas do trabalho com os alunos com necessidades especiais. Descrevem os processos de mudanças da organização e das práticas da EEPCG, que refletiram diretamente em seu cotidiano profissional, exigindo a construção de novos saberes e práticas. Em nossa tentativa de compreender o vivido pelas professoras, consideramos que, no cotidiano de suas práticas, nas relações construídas com os alunos com necessidades especiais, nas relações sociais com as demais professoras, com a diretora, técnicos e analistas da educação da escola, com as famílias, elas constroem territorialidades. Estas se manifestam em atitudes acolhedoras para com seus alunos, nos conflitos existentes e nas indagações sobre o processo de transformação da Educação Especial na direção inclusiva. Assim, ao falar de territorialidades, enfatizamos o caráter simbólico-cultural do território.

$\mathrm{Na}$ escuta que fizemos das entrevistas, o território vivido aparece em toda sua complexidade, revelador do processo sócio-histórico que apresenta aspectos políticos, administrativos, sociais, psicológicos e afetivos. Quando fazemos referência ao território vivido, queremos destacar as relações sociais desenvolvidas, as práticas de trabalho, as viagens, festas e projetos realizados, o dia a dia da instituição escolar. $\mathrm{O}$ vivido permanece vivo para as professoras. A EEPCG, como território, apresenta-se para elas com significados afetivos e emocionais. Podemos afirmar que elas construíram laços territoriais muito fortes com a Educação Especial e com a EEPCG. Haesbaert cita Bonnemaison e Cambrèzy, que afirmam:

O poder do laço territorial revela que o espaço está investido de valores não apenas materiais, mas também éticos, espirituais, simbólicos e afetivos. É assim que o território cultural precede o território político e com ainda mais razão precede o espaço econômico (BONNEMAISON; CAMBRÈZY, 1996, p.10 apud HAESBAERT, 2009, p.72).

Os territórios da Educação Especial e da EEPCG são investidos de valores não só materiais, mas também valores éticos, simbólicos e afetivos, que aparecem nos relatos. Podemos dizer que o trabalho na 
EEPCG propiciou a construção de territorialidades, que as professoras, ao territorializarem essa escola, envolveram-se com seus integrantes, assumiram seus desafios, identificaram-se como defensoras de determinadas causas.

A transformação da Educação Especial no sentido da inclusão e, de maneira específica, a concretização da separação entre a EEPCG e a APAE são portadoras de processos de desterritorialização/reterritorialização. As velhas territorialidades aparecem mais nítidas ou mais fáceis de serem identificadas no processo de desterritorialização, uma vez que as professoras estão reagindo afetivamente às perdas: a perda do espaço físico, antes com maior amplitude, nas formas de acomodação das práticas de trabalho, perda dos alunos que foram incluídos na escola comum e de outros que ficaram na APAE-GV, perda de conceitos e paradigmas, de parcerias institucionais, de laços afetivos e sociais. As novas territorialidades aparecem como forma de organização sob novos padrões legais, novos conhecimentos na perspectiva da educação inclusiva. Entre as velhas e as novas territorialidades, aparecem sempre os laços territoriais desenvolvidos com o trabalho e com os alunos.

Ao refletirmos sobre os processos de desterritorialização/ reterritorialização vividos pelas professoras da Escola Estadual Paulo Campos Guimarães no enfrentamento das transformações da Educação Especial, visualizamos três planos, que são atravessados por esses processos de maneira simultânea: planos histórico-temporal, espacial e simbólico.

Como estratégia de construção de um primeiro elemento de análise desses processos, remetemo-nos ao plano histórico-temporal, pensando na trajetória da escola. Vamos levar em conta as quase três décadas de existência da instituição (1987-2013) e os laços históricos da parceria com APAE/GV no atendimento especializado às pessoas com deficiência. Nessa parceria, as professoras vivenciaram várias situações em que as duas instituições se apresentavam como um só território, em relação ao qual observamos, nas falas das professoras, a presença de um forte sentimento de pertença e identificação. Em sua entrevista, por exemplo, a professora Brígida relata que, quando indagada sobre onde trabalhava, muitas vezes, respondia: "Na escola da APAE". As professoras entrevistadas reconhecem a si mesmas como agentes desse território, relacionando-o com a luta histórica de atendimento às pessoas com necessidades educacionais especiais. 
Nesse contexto, a EEPCG tinha sua posição reforçada pela influência tradicional e representatividade da APAE/GV, que, no cenário dos movimentos sociais, buscava benefícios que também eram transferidos para a escola. Foi a partir dessa ligação inicial com a associação que se constituiu a singularidade da EEPCG, singularidade que se expressa em sua condição particular e exclusiva, no contexto da Educação Especial no município, de escola de ensino especial. As entrevistadas retrataram a construção dessa especificidade no plano histórico-temporal:

"Foi minha primeira experiência. Eu me apaixonei." (professora Edna).

"Olha, é quase metade da minha vida. Eu não consigo me ver trabalhando em outra escola.” (professora Regina).

"É a nossa vida. Não tem como desvincular dessa vida. É lição de vida. É uma experiência e uma lição de vida." (professora Zilma).

Ainda é preciso levar em conta, para compreender a ideia de especificidade, que as professoras têm um legado teórico-prático acumulado, que é respeitado por seus pares e que, ao longo dos anos, tem contribuído com a Educação Especial local.

Esses elementos, analisados no plano histórico-temporal, indicam que, para essas professoras, responder aos novos paradigmas e transformações da Educação Especial significou construir novas práticas e novas lógicas. Mas é importante considerar que esse "novo" faz parte do "antigo". As noções de desterritorialização e reterritorialização ajudam a compreender os movimentos operados por elas frente à necessidade de abandonar territórios antigos, como a parceria com a APAE e as concepções e práticas que orientavam sua atividade docente. Os novos territórios - a identidade da Escola separada da APAE e sua organização como Escola de Educação Especial no contexto da inclusão dos alunos com necessidades especiais na rede regular de ensino - surgem a partir dos antigos, estando por eles atravessados.

Um segundo elemento de análise refere-se ao plano espacial. A mudança de prédio foi um marco de aprofundamento dos processos de desterritorialização/reterritorialização vivenciados pelas professoras da EEPCG em relação aos paradigmas da Educação Especial. Nesse 
momento, o território, vivido em toda sua complexidade, revela uma realidade espacial, que apresenta aspectos administrativos, políticos, sociais e afetivos. As entrevistas mostram que essas dimensões ficam presentes na memória das professoras, em seus processos de desterritorialização. A dimensão simbólica das práticas vividas no prédio da APAE/GV permanece, além da mudança espacial, expressa pelos laços afetivos, sociais e institucionais construídos nos anos de convivência no prédio da APAE/GV. As participantes fazem referência aos espaços físicos partilhados, aos eventos realizados, aos alunos deixados:

"A gente gostaria que tivesse continuado uma coisa só... Fiquei com mágoa da separação... pelos anos de parceria, pelos alunos deixados para trás. Os alunos não entendiam o processo, foi uma família dividida, um processo doloroso." (professora Brígida).

Antes, eu tinha pavor de sair de lá. O prédio era muito bom! A rede física era boa. Puxa vida! As salas eram ótimas, com espaço. Eu achava que tinha que melhorar para funcionar junto, mas as coisas caminharam em outra direção.” (professora Regina).

O sentido da história de vida profissional dessas professoras fica na memória e vai ressurgir na nova EEPCG, que busca firmar sua identidade. As práticas cotidianas no território vivido, espaço de relações sociais e processos de trabalho, dão ritmo à constituição do novo território. Aos poucos, as professoras depositam suas marcas no território que serve como aporte de suas identificações e passam a fazer novos agenciamentos. Isso significa reterritorializar a partir das demandas, respondendo aos estímulos que norteiam a nova estrutura e organização. Entendemos que as novas territorialidades nascem diante desse conjunto de vivências das professoras, que viverão, em outro contexto espacial, outras divisões de espaços e formas de organização de trabalho, permeadas por elementos que remetem, a todo momento, a um território anterior. Como mostra a fala da professora Regina:

"Agora aqui é nossa escola, a nossa escola precisa ser reconhecida. Ela precisa expandir um pouco mais o trabalho." (professora Regina).

Um último elemento a ser analisado nos processos de desterritorialização/reterritorialização das professoras em relação à EEPCG é o 
que chamamos de plano simbólico - conforme Haesbaert (2009, p.40), "a dimensão simbólico-cultural mais subjetiva, em que o território aparece, sobretudo, como produto de apropriação, valorização simbólica de um grupo em relação ao seu espaço vivido". Nesse sentido, buscamos compreender essa valorização simbólica do território vivido na apreensão das ações das professoras em relação à EEPCG. Assinalamos a forte representação simbólica das professoras, em relação à escola, que aparece de modo significativo no texto das entrevistas, através de falas marcantes das subjetividades em relação ao território vivido.

"Essa escola deveria sempre existir, é uma escola humana, solidária [...] A escola é um aprendizado, aprendizado profissional e particular na vida da gente." (professora Brígida).

"A Paulo Campos é sonho de muitos [...] Aqui a gente aprende muito com os alunos, com os colegas de trabalho, aprende pra vida." (professora Brígida).

"A Paulo Campos é um lugar prazeroso... gosto de ser professora aqui... tenho liberdade de fazer o trabalho em que acredito." (professora Regina).

Ao protagonizarem processos de desterritorialização/reterritorialização, as professoras aplicam um modo particular às suas práticas, através do enraizamento na Educação Especial. Isso foi observado no diálogo com as participantes, que, em vários momentos, descreviam recortes de suas práticas de trabalho. Percebe-se que boa parte do saber tradicional, na perspectiva da integração, foi desterritorializado/reterritorializado na perspectiva da educação inclusiva.

Outro elemento que se observa nos movimentos de desterritorialização/reterritorialização tem origem nos processos de formação vivenciados pelas professoras, no campo da inclusão. Nesses momentos de formação, trabalharam aspectos teóricos e práticos da educação inclusiva, refletindo o vivido a partir de um novo paradigma. Em tal processo, constituíram novos saberes e se constituíram como atores de referência da Educação Especial no município. Nas entrevistas, relataram situações nas quais foram convidadas para ministrar cursos e palestras. A formação como elemento do plano simbólico dos processos de desterritorialização/reterritorialização aparece na fala de uma das entrevistadas, que, ao comentar sobre o que aprendera em sua formação, afirma: 
"Acho isso importante para o professor. Quando você sabe... ninguém te olha diferente... pode até questionar, criticar... mas, se você tem consciência de porque, para que você está fazendo, você tem respaldo." (professora Regina).

O plano simbólico está presente nas outras dimensões do território, imbricado nos laços territoriais das professoras com a APAE/GV, a EEPCG e com a Educação Especial, à qual dedicam seu trabalho com alunos que apresentam necessidades educacionais especiais. Podemos dizer que as professoras, nas relações cotidianas com o espaço, alicerçam, constroem dimensões, projetam seus sonhos para o devir da EEPCG. Esse processo de valorização encontra-se também fortemente arraigado na Educação Especial, evidenciado pelas professoras na forma diferenciada de se apropriarem do espaço, a forma simbólica. Assim, podemos fazer uma leitura dos fortes laços que envolvem as professoras e a escola, nos enraizamentos, nas suas práticas de trabalho, nos encontros das relações sociais.

\section{Considerações finais}

Este artigo buscou compreender os processos vivenciados pelas professoras de uma escola de Educação Especial no contexto das transformações da Educação Especial no município de Governador Valadares. Nosso olhar esteve direcionado a essas protagonistas, que, não tão visíveis no processo amplo das transformações da Educação Especial, contribuíram com sua disponibilidade em participar da pesquisa e nos apresentaram, sob a forma de relatos, suas práticas e trajetórias vividas na EEPCG. Os processos de transformações protagonizados pelas professoras demarcam conflitos subjetivos, explicitados pelos desejos e pela resistência em relação às rápidas mudanças da Educação Especial.

Neste trabalho, procuramos contribuir para a compreensão dessas transformações de uma maneira nova, qual seja, sob o olhar dos estudos do território. Assim, analisamos os processos vivenciados pelas professoras como processos de desterritorialização/reterritorialização, compreendidos nos planos histórico-temporal, espacial e simbólico. As professoras reterritorializaram as práticas de organização e funciona- 
mento da EEPCG, suas práticas pedagógicas e a própria instituição. Esses processos são marcados por modificações de códigos, símbolos e saberes que conduziram para novas territorialidades. Caminhos investigativos podem ser desenhados com a utilização dos conceitos de estudos territoriais, que abrem uma nova possibilidade de investigação e compreensão dos fenômenos educacionais.

\section{NOTA}

${ }^{1}$ Cf. também: "Em primeiro lugar, há, em um agenciamento, como que duas faces ou, ao menos, duas cabeças. Estados de coisas, estados de corpos (os corpos se penetram, se misturam, se transmitem afetos); mas também enunciados, regimes de enunciados. [...] Os enunciados são peças e engrenagens no agenciamento, não menos que os estados de coisas. [...]. Os enunciados não se contentam em descrever estado de coisas correspondentes: são, antes, como duas formalizações não paralelas, formalização de expressão e formalização de conteúdo, tais como nunca se faz o que se diz, nunca se diz o que se faz, mas não é por isso que se mente, nem por isso que se engana e se engana a si mesmo, agenciam-se apenas signos e corpos como peças heterogêneas da mesma máquina" (DELEUZE; PARNET, 1998, p.85).

\section{REFERÊNCIAS}

BRASIL. Ministério da Educação. Direito à educação: necessidades educacionais especiais/subsídios para atuação do Ministério Público Brasileiro. Brasília: Secretaria de Educação Especial, 2001.

DELEUZE, Gilles; GUATTARI, Félix. O que é a Filosofia? Lisboa: Presença, 1992.

DELEUZE, Gilles; GUATTARI, Félix. Mil platôs: capitalismo e esquizofrenia. São Paulo: Ed. 34, 2009. v.1.

EIZIRIK, Marisa Faermann. A inclusão como dispositivo. Ensaios Pedagógicos, Brasília, MEC/SEESP, p.39-49, 2007.

ESCOLA ESTADUAL PAULO CAMPOS GUIMARÃES. Regimento escolar. Governador Valadares, 1994. (mimeo).

ESCOLA ESTADUAL PAULO CAMPOS GUIMARÃES. Projeto político-pedagógico. Governador Valadares, 2009/2010. (mimeo.).

ESCOLA ESTADUAL PAULO CAMPOS GUIMARÃES. Histórico da Escola Estadual Paulo Campos Guimarães. Governador Valadares, 2006. (mimeo.).

FRANCO, Maria Amélia Santoro. Pedagogia como ciência da educaşão. São Paulo: Papirus, 2003. 
GUATTARI Félix; RONILK, Suely. Micropolítica: cartografias do desejo. 10ed. Rio de Janeiro: Vozes, 2010.

HAESBAERT, Rogério; BRUCE, Glauco. A desterritorialização na obra de Deleuze e Guattari. Revista GEOgraphia, Niterói, ano IV, n.7, p.7-31, 2002.

HAESBAERT, Rogério; BRUCE, Glauco. Desterritorialização: entre as redes e os aglomerados de exclusão. In: CASTRO, I. E.; GOMES, P. C.; CORRÊA, R. L. (Orgs.) Geografia: conceitos e temas. Rio de Janeiro: Bertrand Brasil, 2003. p.166-205.

HAESBAERT, Rogério; RAMOS, Tatiana Tramontani. O mito da desterritorialização econômica. Revista GEOgraphia, Rio de Janeiro, v.6, n.12, p.25-48, 2004.

HAESBAERT, Rogério. O mito da desterritorialização: do "fim dos territórios" à multiterritorialidade. 4ed. Rio de Janeiro: Bertrand Brasil, 2009.

MANTOAN, Maria Teresa. Inclusão escolar: o que é? Por quê? Como fazer? São Paulo: Moderna, 2006.

RODRIGUES, Davi. Questões preliminares sobre o desenvolvimento de políticas de educação inclusiva. Inclusão, Revista da Educação Especial, Brasília, v.4, n.1, p.33-40, jan./jun. 2008.

SAQUET, Marcos Aurélio. Proposições para estudos territoriais. Geografia, Paraná, ano VIII, n.15, p.71-85, 2006.

SAQUET, Marcos Aurélio. As diferentes abordagens do território e apreensão do movimento e da (i)materialidade. Geosul, Florianópolis, v.22, n.43, p.55-76, jan./jun. 2007.

SAQUET, Marcos Aurélio. Abordagens e concep̧̧ões de território. 2.ed. São Paulo: Expressão Popular, 2010.

TURINO, Flávia Ferreira. Consumo, logo apareço: produção de subjetividades juvenis na cultura e consumo e do espetáculo. 180f. Tese (Doutorado em Psicossociologia de Comunidades e Ecologia Social) - Universidade Federal do Rio de Janeiro, Rio de Janeiro, 2010.

UNESCO. Declaração de Salamanca: linha de ação sobre necessidades educativas especiais. Brasília: CORDE, 1994.

Recebido em: 11/06/2013

Aprovado em: 13/11/2013

Contato:

Rua Tiradentes, 199/ 1001

Centro

CEP 35020-610

Governador Valadares | MG | Brasil 